\title{
Chimps lead evolutionary race
}

Humans are generally believed to be more highly 'evolved' than our chimpanzee cousins. But in at least one sense that isn't true, say geneticists who have hunted for the hallmarks of natural selection in our respective genomes - and found more of them in chimps.

The discovery suggests that, since our evolutionary paths diverged 6 million years ago, greater numbers of chimpanzee genes have been shaped by 'positive selection', in which natural selection favours beneficial mutations.

Researchers at the University of Michigan, Ann Arbor, combed through 14,000 matching genes from the human and chimpanzee genomes. As they report in Proceedings of the National Academy of Sciences this week, 233 chimp genes showed signs of having been shaped by positive selection (M. A. Bakewell, P. Shi and J. Zhang Proc. Natl Acad. Sci. USA doi:10.1073/pnas.0701705104; 2007). The corresponding figure for our own genes was just 154 .

The result overturns the view that, to promote humans to our current position as the dominant animal on the planet, we must have encountered considerable positive selection, says lead author Jianzhi Zhang. "We think we're very different from animals, with our large brain size and speech," he says.

The gene discrepancy might be due to the fact that, for much of our histories, chimpanzees had the larger population size. Humans, with a smaller and more fragmented population, may have been shaped by random, erratic changes.

It is difficult to put together a coherent picture, says Zhang, because it is hard to know which genes would have been crucial in shaping traits such as our large brain size. "It is possible that the genetic changes underlying brain size are very few," he says.

A sample of 14,000 genes does not tell the whole story. The team could not compare the entire genome as the chimp sequence has not been completed to the same level of detail as the human one. But for genes with good sequences, they were taken to show signs of positive selection if they had a high proportion of 'nonsynonymous mutations' - DNA changes that alter the protein sequence produced by the gene - which could be a 'lever' for natural selection.

Zhang admits it is difficult to spot genes that have been the subject of more recent positive selection. Such genes could have been responding to selection pressures - such as changes in climate and food source - encountered by humans as they began to move out of Africa and across the planet over the past 100,000 years.

There also seems to be little pattern to the functions of the selected genes, says Zhang. Among those favoured in chimps are genes for protein metabolism and stress responses, whereas the human genes are involved in processes such as fatty-acid metabolism.

Victoria Horner, who works with chimpanzees at Yerkes National Primate Research Center in Atlanta, Georgia, says: "We assume that chimpanzees have changed less than us, when that's actually not the case."

Michael Hopkin

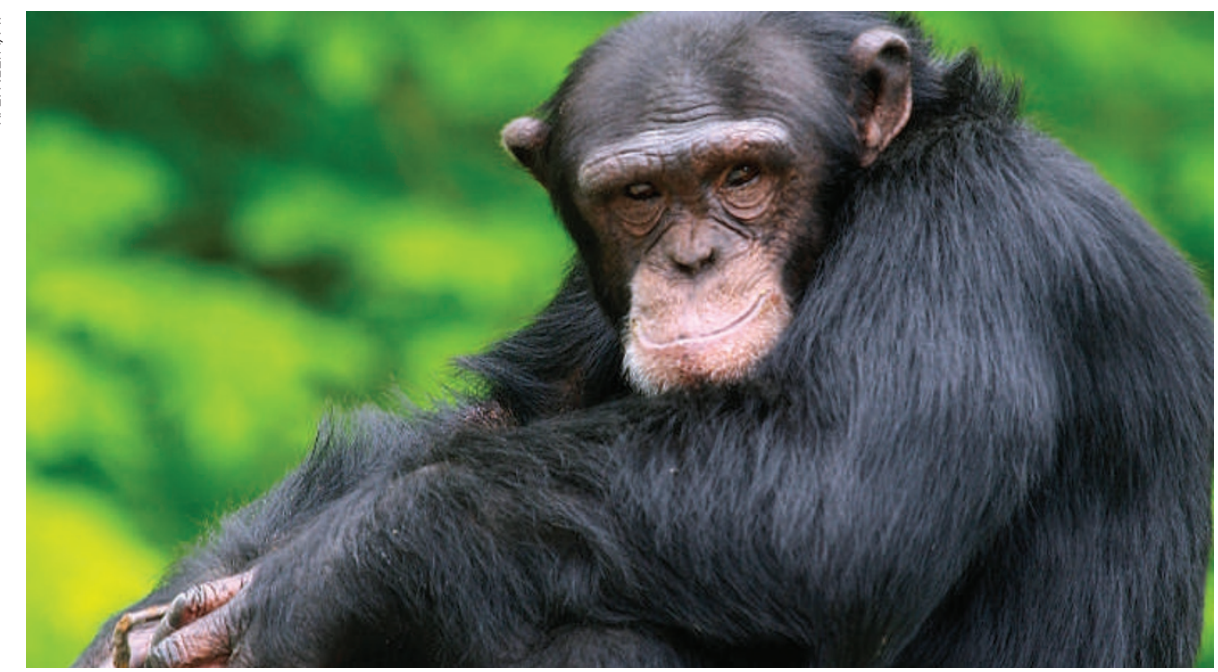

Chimpanzees have at least 233 genes thought to be shaped by selection for beneficial mutations.

\section{ZOO NEWS}

\section{Dial-up dolphin}

Castaway, a deaf dolphin at the

Marine Mammal Conservancy in Key Largo, Florida, has become the proud recipient of a 'chat line' that will broadcast the sounds of nearby dolphins and help the unborn calf in her uterus learn vital sonar and social skills.

\section{SCORECARD}
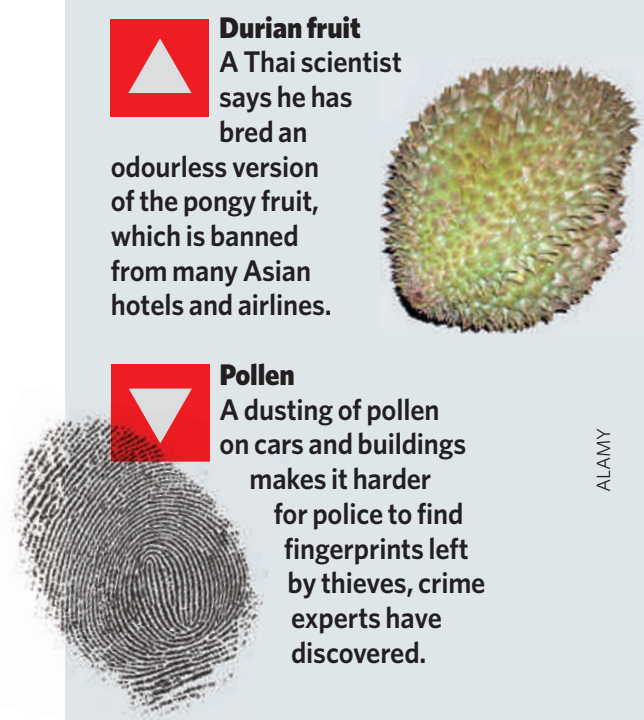

\section{NUMBER CRUNCH}

$8 \%$ is the amount that New York City's greenhouse-gas emissions have risen between 1995 and 2005.

\section{3 million tonnes} is the amount of greenhouse gas emitted by the city in 2005 - almost as much as the entire Republic of Ireland, but just 1\% of total US emissions.

$2.7 \%$ is the proportion of the US population that lives in the city - making New Yorkers almost three times greener, on average, than the typical American.

\section{ON THE RECORD}

\section{C(It would be the wrong thing to do to select people who aren't going to fit in your spaceship.")}

Duane Ross demonstrates exactly why he is NASA's head of astronaut selection.

Sources: ABC News, Associated Press, The Independent, USA Today 